\section{(6) OPEN ACCESS}

\title{
Hyponatraemia in patients with crush syndrome during the Wenchuan earthquake
}

\author{
Li Zhang, ${ }^{1}$ Ping Fu, ${ }^{2}$ Li Wang, ${ }^{3}$ Guangyan Cai, ${ }^{1}$ Lin Zhang, ${ }^{4}$ Dezheng Chen, ${ }^{5}$ \\ Dongyang Guo, ${ }^{6}$ Xuefeng Sun, ${ }^{1}$ Fuqiong Chen, ${ }^{7}$ Weihong $\mathrm{Bi}^{8}{ }^{8}$ Xinjie Zeng, ${ }^{9}$ Haiyan $\mathrm{Li}_{1}{ }^{10}$ \\ Zhaohui Liu, ${ }^{11}$ Yong Wang, ${ }^{1}$ Songmin Huang, ${ }^{2}$ Xiangmei Chen, ${ }^{1}$ for the Wenchuan \\ earthquake-related AKI study group
}

\begin{abstract}
${ }^{1}$ State Key Laboratory of Kidney Disease, Chinese PLA General Hospital, Beiijng, China ${ }^{2}$ Department of Nephrology, Huaxi Hospital, Sichuan University, Chengdu, China ${ }^{3}$ Department of Nephrology, Sichuan People's Hospital, Chengdu, China

${ }^{4}$ Department of Nephrology, Mianyang Central Hospital, Mianyang, China

${ }^{5}$ Department of Nephrology, Jianyang People's Hospital, Jianyang, China

${ }^{6}$ Department of Nephrology, General Hospital of Chengdu Military Region, Chengdu, China Department of Nephrology, 404 Hospital of Mianyang, Mianyang, China

${ }^{8}$ Department of Nephrology, Third People's Hospital of Mianyang City, Mianyang, China ${ }^{9}$ Department of Nephrology, Guangyuan City Central Hospital, Guangyuan, China ${ }^{10}$ Department of Nephrology, Deyang City People's Hospital, Deyang, China

${ }^{11}$ Department of Nephrology,

The Second Hospital in

Chengdu, Chengdu, China
\end{abstract}

\section{Correspondence to}

Professor Xiangmei Chen, State Key Laboratory of Kidney Disease, Chinese PLA General Hospital, 2011DAV00088, 28 Fuxing Road, Beijing 100853, People's Republic of China; xmchen301@126.com

Accepted 22 August 2012 Published Online First 26 September 2012

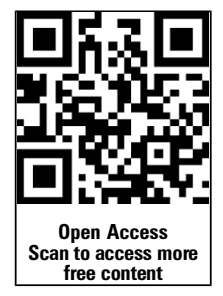

\section{ABSTRACT}

Background Although sodium disturbances are common in hospitalised patients, no study has specifically investigated the epidemiology of hyponatraemia in patients with crush syndrome.

Objectives To describe the incidence of hyponatraemia and assess its effect on outcome in patients with crush syndrome during the Wenchuan earthquake.

Methods A retrospective study was conducted in 17 reference hospitals during the Wenchuan earthquake. We excluded patients younger than 15 years and those with missing sodium values within 3 days after being rescued from the ruins.

Results Hyponatraemia (serum sodium concentration $<135 \mathrm{mmol} / \mathrm{l})$ was seen in $91 / 180(50.6 \%)$ patients on admission. Compared with patients with normonatraemia, those with hyponatraemia were younger, had more severe traumatic injury and renal failure, underwent more fasciotomies, received more blood transfusion and renal replacement therapy. In the multivariable-adjusted model, the number of extremity injuries $(\mathrm{OR}=1.59,95 \% \mathrm{Cl} 1.08$ to 2.33 ) and serum creatinine $(\mathrm{OR}=1.30,95 \% \mathrm{Cl} 1.07$ to 1.59) were independently associated with the occurrence of hyponatraemia. Covariate adjusted multiple logistic regression analysis showed an independent mortality risk rising with hyponatraemia $(\mathrm{OR}=5.74,95 \% \mathrm{Cl} 1.18$ to 28.00)

Conclusions Hyponatraemia was common in the patients with crush syndrome during the Wenchuan earthquake and associated with poor prognosis. Water, commercial drinks and hypotonic intravenous fluids should be supplied carefully to patients with crush syndrome.

\section{INTRODUCTION}

Hyponatraemia is the most common electrolyte disorder in adult patients admitted to the intensive care unit (ICU). The prevalence of hyponatraemia on ICU admission is between $13.7 \%$ and $17.7 \%{ }^{12}$ The risk of death during hospitalisation is increased in patients admitted to hospital with hyponatraemia compared with normonatraemia. ${ }^{3}$ Hyponatraemia present on admission to the ICU is an independent risk factor for poor prognosis. ${ }^{1}$

Earthquake disasters result in a vast number of instant deaths owing to injuries to vital organs, and are also associated with a cluster of heavily wounded people, in whom crush injuries and prolonged compression of limbs are commonly found. Crush syndrome is the systemic manifestation of muscle cell damage resulting from crushing and affects many organs, resulting in hypovolaemic shock, acute kidney injury (AKI), arrhythmias, acute respiratory distress syndrome, sepsis and electrolyte disturbances. ${ }^{4}$ Crush injury-related electrolyte abnormalities that occur as a result of the release of cellular components include hyperkalaemia, hyperphosphataemia, high aniongap metabolic acidosis and hypermagnesaemia. ${ }^{5}$ Hyponatraemia is seldom reported in patients with crush syndrome in hospital as it is one of the most common electrolyte disorders found.

On 12 May 2008, western Sichuan in China was devastated by a deadly earthquake measuring 8.0 on the Richter scale, which was named the Wenchuan earthquake. The earthquake caused 69227 deaths, 17923 people were lost and 96544 wounded. The disaster also resulted in hundreds of patients with crush syndrome. ${ }^{6}$ The primary aim of this study is to describe the incidence of hyponatraemia and assess its effect on outcome in patients with crush syndrome. The study protocol was approved by the ethic committee of the Chinese PLA General Hospital.

\section{MATERIALS AND METHODS \\ Data collection}

The Wenchuan earthquake-related AKI study group designed a questionnaire in accordance with the recommendations of the International Society of Nephrology's Renal Disaster Relief Task Force. The questionnaire was sent to 17 hospitals, in which the casualties were accepted and dialysis was available. Among a total of 286 feedback questionnaires, 242 from 10 centres met the criteria of crush syndrome. Double registrations were found in 14 patients. To avoid repetition, duplicate records were combined as one. ${ }^{6}$

\section{Definitions}

Crush syndrome was defined as crush injury with one of the following characteristics: urine output $<400 \mathrm{ml} /$ day, blood urea nitrogen $>14.3 \mathrm{mmol} / \mathrm{l}$, serum creatinine $>176.8 \mu \mathrm{mmol} / 1$, serum uric acid $>475.8 \mu \mathrm{mmol} / \mathrm{l}$, serum potassium $>6 \mathrm{mmol} / \mathrm{l}$, phosphorus $>2.6 \mathrm{mmol} / 1$ or calcium $<2 \mathrm{mmol} / \mathrm{l}^{7}$

The initial serum sodium concentration in this analysis was adjusted according to the concomitantly measured serum glucose level. If the glucose level was $>5.55 \mathrm{mmol} / \mathrm{l}$, the serum sodium level was adjusted upward by $2 \mathrm{mmol} / \mathrm{l}$ for each $5.55 \mathrm{mmol} / 1$ increment in serum glucose. ${ }^{8}$ Normal serum sodium was defined as $135-145 \mathrm{mmol} / \mathrm{l}$. 
Hyponatraemia was defined as a serum sodium concentration $<135 \mathrm{mmol} / \mathrm{l}$. Hypernatraemia was defined as a serum sodium concentration $>145 \mathrm{mmol} / 1$.

Based on the diagnoses in the hospitals, injury severity was measured by the Injury Severity Score (ISS). ${ }^{9} 10$

\section{Statistical analysis}

Descriptive statistics of all numerical variables, including means, SD, together with the proportions of all categorical variables were calculated. Measurement data between the groups were compared by Student $t$ test or Mann-Whitney test according to whether or not they conformed to normal distribution. Differences between group proportions were examined with a $\chi^{2}$ test. Multivariate logistic regression analysis was performed to assess the possible predictors of hyponatraemia and mortality. Data were analysed by standard statistical software (SPSS V.13.0, Chicago, Illinois, USA).

\section{RESULTS}

A total of 228 patients with crush syndrome were admitted to 10 reference hospitals after the earthquake. Seventeen paediatric patients were excluded and 31 patients were not analysed owing to the absence of serum sodium values within 3 days after being rescued from the ruins. One hundred and eighty patients were included in this analysis. Of these 180 patients, 11 (6.1\%) were hypernatraemic and 91 (50.6\%) were hyponatraemic. After excluding the patients with hypernatraemia, the final analytical dataset comprised 169 patients with normonatraemia or hyponatraemia.

The characteristics of the study population at admission are summarised in table 1. The hyponatraemic patients were significantly younger than those with normonatraemia. The distribution of gender was similar in both groups. No significant differences were found in body temperature, heart rate, blood pressure and time spent under the ruins between the two groups, but a significantly lower urine output in the first $24 \mathrm{~h}$ was recorded in the hyponatraemic group.

For the laboratory data at admission, there were no significant differences in haemoglobin, white blood cell (WBC) count, platelet and serum albumin between the hyponatraemic and normonatraemic patients. Compared with normonatraemic patients, serum creatinine, blood urea nitrogen, potassium, phosphorus, uric acid and creatinine kinase were significantly higher, while serum calcium was significantly lower in hyponatraemic patients (table 1).

There were no significant differences in ISS, the incidence of chest and abdominal trauma between the two groups. Traumatic brain injury was seen in six patients in the hyponatraemic group, while none was found in the normonatraemic group (table 2). The incidence of medical complications, including traumatic shock, wound infection, sepsis, pneumonia, respiratory failure, acute respiratory distress syndrome and disseminated intravascular coagulation, did not differ significantly between the two groups. The hyponatraemic patients had a greater number of multiple extremity injuries and underwent more fasciotomies than the normonatraemic patients (table 2). The number of multiple extremity injuries showed positive correlations with serum creatinine $(r=0.218, p=0.005)$ and potassium $(r=0.362, p<0.001)$, while negative correlations were noted with urine output $(r=-0.175, p=0.034)$, serum albumin $(\mathrm{r}=-0.243, \mathrm{p}=0.003)$ and calcium $(\mathrm{r}=-0.187, \mathrm{p}=0.031)$

The quantity of fluids administered within the first $24 \mathrm{~h}$ of their hospitalisation was defined in 89 patients and the mean total volume was $3229 \pm 2328 \mathrm{ml}$ (range 300-10 $360 \mathrm{ml}$ ). Only $17 / 169$ patients $(10.1 \%)$ received fluid infusion $>6000 \mathrm{ml} / 24 \mathrm{~h}$. There was no significant difference in the volume of fluids administered between the hyponatraemic and normonatraemic patients. The hyponatraemic group received more blood transfusions, while no significant difference was found in plasma transfusions between the two groups. Renal replacement therapy was performed more often in patients with hyponatraemia than in those with normal serum sodium level (table 3).

Multivariate logistic regression analysis adjusted by age including the variables of number of extremity injuries, serum creatinine, potassium, phosphorus and calcium indicated that number of extremity injuries $(\mathrm{OR}=1.59,95 \% \mathrm{CI} 1.08$ to 2.33$)$ and serum creatinine ( $\mathrm{OR}=1.30,95 \% \mathrm{CI} 1.07$ to 1.59$)$ were independently associated with the occurrence of hyponatraemia.

Overall, 14 (15.4\%) hyponatraemic patients died, while 4 $(5.1 \%)$ deaths were noted in the normonatraemic patients

Table 1 Characteristics of patients with and without hyponatraemia

\begin{tabular}{|c|c|c|c|c|c|}
\hline Characteristics & Normal sodium & Patients (n) & Hyponatraemia & Patients (n) & p Value \\
\hline Male (\%) & $37(47.4)$ & 78 & $53(58.2)$ & 91 & 0.160 \\
\hline Urinary volume $(\mathrm{ml} / 24 \mathrm{~h})$ & $889.7 \pm 738.1$ & 69 & $619.6 \pm 704.3$ & 78 & 0.004 \\
\hline ISS & $11.2 \pm 7.0$ & 78 & $12.7 \pm 10.2$ & 91 & 0.381 \\
\hline Systolic blood pressure (mm Hg) & $119.8 \pm 32.9$ & 78 & $115.6 \pm 30.2$ & 89 & 0.797 \\
\hline WBC count $\left(10^{9} / 1\right)$ & $13.0 \pm 6.6$ & 77 & $13.8 \pm 6.3$ & 87 & 0.155 \\
\hline Platelets $\left(10^{9} / 1\right)$ & $114.4 \pm 65.0$ & 77 & $124.1 \pm 62.0$ & 87 & 0.328 \\
\hline Serum albumin $(g / l)$ & $27.7 \pm 8.3$ & 70 & $26.3 \pm 6.4$ & 78 & 0.641 \\
\hline Serum creatinine (mg/dl) & $2.8 \pm 1.8$ & 78 & $4.3 \pm 2.5$ & 91 & $<0.001$ \\
\hline Blood urea nitrogen (mg/dl) & $49.6 \pm 25.2$ & 78 & $68.6 \pm 31.6$ & 91 & $<0.001$ \\
\hline Creatinine kinase (U/l) & $20395.6 \pm 50660.4$ & 34 & $81083.3 \pm 229550.7$ & 42 & 0.006 \\
\hline
\end{tabular}

ISS, Injury Severity Score; WBC, white blood cell. 
Table 2 Incidence of traumatic events in patients with and without hyponatraemia

\begin{tabular}{lccc}
\hline Traumatic events & $\begin{array}{l}\text { Normonatraemia } \\
(\mathbf{N}=\mathbf{7 8})\end{array}$ & $\begin{array}{l}\text { Hyponatraemia } \\
(\mathbf{N}=\mathbf{9 1})\end{array}$ & p Value \\
\hline $\begin{array}{l}\text { Number of crushed } \\
\text { extremities }\end{array}$ & $1.3 \pm 0.9$ & $2.1 \pm 1.4$ & $<0.001$ \\
Fracture (n, \%) & $43(55.1)$ & $37(40.7)$ & 0.092 \\
Traumatic shock (n, \%) & $10(12.8)$ & $6(6.6)$ & 0.168 \\
Thoracic trauma $(\mathrm{n}, \%)$ & $16(20.5)$ & $23(25.3)$ & 0.464 \\
Abdominal trauma $(\mathrm{n}, \%)$ & $11(14.1)$ & $9(9.9)$ & 0.398 \\
Cerebral trauma $(\mathrm{n}, \%)$ & 0 & $6(6.6)$ & 0.031 \\
\hline
\end{tabular}

$(p=0.040)$. Compared with patients with a normal serum sodium level, the occurrence of hyponatraemia was independently associated with a higher risk of in-hospital mortality $(\mathrm{OR}=3.36,95 \%$ CI 1.06 to 10.69). The adjusted risk of mortality was also more prominent in patients with hyponatraemia $(\mathrm{OR}=5.74,95 \%$ CI 1.18 to 28.00$)$.

\section{DISCUSSION}

In this study we describe for the first time the prevalence of hyponatraemia in patients with crush syndrome after an earthquake. It demonstrates that hyponatraemia is common in patients with crush syndrome, and associated with poor prognosis.

Although many reports have examined the prevalence, causes and outcomes of hyponatraemia, few have focused on hyponatraemia associated with crush syndrome. Oda et al retrospectively analysed eight patients with crush syndrome who were treated in the ICU of a university hospital. Reduced serum sodium concentrations, ranging from 119 to $133 \mathrm{mmol} / \mathrm{l}$, were present in six patients. ${ }^{11}$ Dönmez et al reported on 20 paediatric patients with crush syndrome, with serum sodium levels of 135.4 and $133 \mathrm{mmol} / \mathrm{l}$ in children with one extremity and multiple extremity injuries, respectively, meaning that nearly half of the patients developed hyponatraemia. ${ }^{12}$ Adams et al recently conducted a prospective, observational study showing that AKI was present in $32 \%$ of patients with hyponatraemia. ${ }^{13}$ However, these three studies all included small numbers of patients. In our study, hyponatraemia was detected in $50.6 \%$ of 180 adult patients with crush syndrome on admission, which is higher than that in unselected patients. In a prospective cohort study of 98411 adults, hyponatraemia was seen in $14.5 \%$ of patients on initial measurement. ${ }^{3}$ Another retrospective study including 151486 adults in 77 ICUs showed that the frequency of hyponatraemia in critically ill patients was $17.7 \%{ }^{1}$

Table 3 Therapeutic interventions in patients with and without hyponatraemia

\begin{tabular}{lllr}
\hline $\begin{array}{l}\text { Therapeutic } \\
\text { interventions }\end{array}$ & $\begin{array}{l}\text { Normonatraemia } \\
(\mathbf{N}=\mathbf{7 8})\end{array}$ & $\begin{array}{l}\text { Hyponatraemia } \\
\mathbf{( N = 9 1 )}\end{array}$ & $\mathbf{p}$ Value \\
\hline Fasciotomies (n, \%) & $21(26.9)$ & $41(45.1)$ & 0.015 \\
Amputations (n, \%) & $28(35.9)$ & $34(37.4)$ & 0.844 \\
Fluid transfusion during & $3424.5 \pm 2532.3$ & $3054.9 \pm 2136.6$ & 0.408 \\
1st 24 h (ml) & & & \\
Blood transfusion (U) & $7.5 \pm 19.6$ & $14.2 \pm 29.6$ & 0.037 \\
Plasma transfusion (ml) & $1807.3 \pm 4815.8$ & $3000.0 \pm 6376.3$ & 0.140 \\
Dialysis (n, \%) & $31(44.1)$ & $65(75.3)$ & $<0.001$ \\
\hline
\end{tabular}

Although the causes of hyponatraemia are varied, from a pathophysiological point of view, hypotonic hyponatraemia is the most common type, which is commonly caused by non-osmotic release of vasopressin. ${ }^{14}$ This is especially true among patients with crush syndrome. After being crushed and trapped by debris during the earthquake, the victims had severe pain and extreme fear, which stimulated the release of vasopressin. Prolonged compression caused muscle ischaemia, and reperfusion contributed additionally to the injury. The sarcolemma loses its functional integrity, creating intracellular oedema and third-space loss, resulting in intravascular volume depletion, ${ }^{15}$ which promotes homoeostatic activation of the renin-angiotensin system, vasopressin and the sympathetic nervous system. ${ }^{16}$ Westermann et al found that vasopressin was significantly increased in patients with multiple trauma. ${ }^{17}$ In our series, the patients with hyponatraemia had more severe traumatic injury, and hyponatraemia is independently associated with the number of crushed extremities, which reflected more third-space loss and the severity of the hypovolaemic condition. The decrease of urine output in the first $24 \mathrm{~h}$ also reflected the impaired ability of the kidney to excrete water, at least partly owing to increased vasopressin.

Although time spent under the ruins did not differ between the two groups, we could not exclude the possibility that after being rescued after prolonged periods in the rubble, the victims tended to drink large amounts of water to relieve thirst due to dehydration. It is possible for muscle compartments of a $75 \mathrm{~kg}$ adult to lose up to 12 litres of fluid in the first $48 \mathrm{~h} .{ }^{18}$ Therefore, vigorous fluid replacement is imperative to prevent hypovolaemia and acute renal failure. ${ }^{19}$ Unfortunately, during a large-scale disaster, provision of fluids is more difficult to implement. Although for some victims of the Wenchuan earthquake fluid administration started before extrication from beneath the rubble, the fluid resuscitation was not as vigorous as recommended. ${ }^{4}{ }^{19}$ Only $10.1 \%$ of patients with AKI received fluid infusion of $>6000 \mathrm{ml}$ within the first $24 \mathrm{~h}$ of their hospitalisation The reasons for this include a shortage of medical supplies and lack of experience in dealing with crush-related AKI.

The same patterns were also reported in the Kobe earthquake $^{20}$ and the Marmara earthquake. ${ }^{21}$ In the Kobe earthquake, most of the victims with crush syndrome received only $2000-3000 \mathrm{ml} /$ day of infused fluids during the initial 3 days, and the mean volume of administered fluids was $5109 \mathrm{ml} /$ day in the Marmara earthquake. In this setting, the victims might drink more water or commercial drinks. However, even the commercial sports drinks are hypotonic, with a sodium concentration of only about $18 \mathrm{mmol} / \mathrm{l}^{22}{ }^{23}$ As a result, victims are prone to develop hyponatraemia owing to a relative excess of hypotonic fluid in conjunction with an underlying condition that impairs the kidney's ability to excrete water.

Although a number of reviews have mentioned renal failure as an important contributor to impaired renal water excretion, few cohorts with AKI and hyponatraemia have been reported. Adams et al recently conducted a prospective, observational study showing that $32 \%$ of the patients with hyponatraemia had AKI, most of which were prerenal AKI. ${ }^{13}$ A characteristic feature of crush syndrome-related AKI is the presence of a low fractional excretion of sodium $(<1 \%)$, reflecting the primacy of preglomerular vasoconstriction and tubular occlusion rather than tubular necrosis. ${ }^{16} 24$ Adams et al suggested that AKI and hyponatraemia should be regarded as two different manifestations of one underlying cause. ${ }^{13}$ In our study, although we could not determine whether the patients at hospital admission 
presented with prerenal failure, we found that the serum creatinine level was another predictor of hyponatraemia.

Hyponatraemia has been shown to be a powerful risk factor for both morbidity and mortality. Hyponatraemia present on admission to the ICU is an independent risk factor for poor prognosis. ${ }^{1}$ Recently, a large single-centre study showed that both community and hospital-acquired hyponatraemia were associated with increased mortality even when hyponatraemia was mild. ${ }^{3}$ It remains unclear whether the relationship between hyponatraemia and adverse outcomes is causative or only associative. Chawla et al reported that the nature of underlying illness rather than the severity of hyponatraemia best explained mortality associated with hyponatraemia. ${ }^{25}$ In our study, patients with hyponatraemia had more severe traumatic injury and renal failure, underwent more fasciotomies, received more blood transfusion and renal replacement therapy. Although it is hard to reach a definite conclusion that a direct relationship exists between hyponatraemia and mortality, the OR was still highly significant after adjustment for comorbidity, emphasising the association between hyponatraemia and a poor clinical outcome.

The potential morbidity and mortality from hyponatraemia provide the rationale for trying to maintain normonatraemia in all patients. ${ }^{25}$ To prevent renal failure ${ }^{419}$ and hyponatraemia in patients with crush syndrome, early, aggressive volume repletion before evacuating the patients is crucial. Adams et al reported that isotonic fluid replacement could correct hyponatraemia without overcorrection and led to a good outcome. ${ }^{13}$ Because patients with crush syndrome have a greater tendency to develop hyponatraemia, these data emphasise that isotonic saline is the preferred repletion fluid. Water, commercial drinks and hypotonic intravenous fluids should be given cautiously to patients with crush injury.

This study has several limitations. First, our data included a number of missing values owing to the chaotic disaster conditions. This study did not obtain data on prehospital oral or intravenous fluids, which might be an important reason for the development of hyponatraemia in patients with crush syndrome during the earthquake. Lack of information about urine osmolality and sodium excretion rate made it difficult to assess the fluid balance and its cause. However, owing to delay in extricating people from the ruins and the long distance of transportation as well as the severe rhabdomyolysis, most patients in this study had already developed acute renal failure on admission, and thus assessment of the above values might not be as important as in the general population.

\section{CONCLUSIONS}

Hyponatraemia was common in the patients with crush syndrome during the Wenchuan earthquake and associated with poor prognosis. Water, commercial drinks and hypotonic intravenous fluids should be supplied carefully to patients with crush syndrome.

Acknowledgements We thank the members of the Wenchuan earthquake related AKI study group: Huaxi Hospita: Dr Zhangxue Hu, Dr Wei Qin; Sichuan People's Hospital: Dr Guiseng Li; Mianyang Central Hospital: Dr Xiaohui Gan; 404 Hospital of Mianyang, Dr Xun Jian; Third People's Hospital of Mianyang City: Dr Tingting Wang. We would like to thank all people who indirectly participated in various parts of this study; all doctors and nurses involved in earthquake relief from all over the country and from international organisations.
Contributors LZ, XC, PF, GC, SH: participated in the study design, data analysis and interpretation. LZ: drafted the manuscript. $X C$ : is the guarantor and critically revised the manuscript. LZ, PF, LW, LZ, DC, DG, XS, FC, WB, XZ, HL, ZL: performed the data collection and analysis. YW: participated in data analysis, interpretation and critical revisions of the manuscript.

Funding This study was supported by the grants from Chinese PLA 12th Five-Year Plan for Medical Sciences (BWS11J027) and National Natural Science Foundation of China (81170643).

\section{Competing interests None.}

Ethics approval Ethic sommittee of the Chinese PLA General Hospital.

Provenance and peer review Not commissioned; externally peer reviewed.

Open Access This is an Open Access article distributed in accordance with the Creative Commons Attribution Non Commercial (CC BY-NC 3.0) license, which permits others to distribute, remix, adapt, build upon this work non-commercially, and license their derivative works on different terms, provided the original work is properly cited and the use is non-commercial. See: http://creativecommons.org/licenses/by-nc/3.0/

\section{REFERENCES}

1. Funk G-C, Lindner G, Druml W, et al. Incidence and prognosis of dysnatremias present on ICU admission. Intensive Care Med 2010;36:304-11.

2. Bennani SL, Abouqal R, Zeggwagh AA, et al. Incidence, causes and prognostic factors of hyponatremia in intensive care. Rev Med Interne 2003;24:224-29.

3. Waikar SS, Mount DB, Curhan GC. Mortality after hospitalization with mild, moderate and severe hyponatremia. Am J Med 2009;122:857-65.

4. Sever MS, Vanholder R, Lameire N. Management of crush-related injuries after disasters. N Engl J Med 2006;354:1052-63.

5. Bywaters EG, Beall D. Crush injuries with impairment of renal function. 1941. J Am Soc Nephro 1998;9:322-32.

6. Zhang L, Fu P, Wang $L$, et al. The clinical features and outcome of crush patients with acute kidney injury after the Wenchuan earthquake: differences between elderly and younger adults. Injury 2012;43:1470-5.

7. Sever MS, Erek E, Vanholder $\mathrm{R}$, et al. The Marmara earthquake: epidemiological analysis of the victims with nephrological problems. Kidney Int 2001;60:1114-23.

8. Wald R, Jaber BL, Price LL, et al. Impact of hospital-associated hyponatremia on selected outcomes. Arch Intern Med 2010;170:294-302.

9. Osler T, Baker SP, Long W. A modification of the injury severity score that both improves accuracy and simplifies scoring. J Trauma 1997;43:922-25.

10. Committee on Injury Scaling. The Abbreviated Injury Scale: 1998 revision (A/S-98). Des Plaines, IL: Association for the Advancement of Automotive Medicine.

11. Oda Y, Shindoh M, Yukioka H, et al. Crush syndrome sustained in the 1995 Kobe, Japan, earthquake; treatment and outcome. Ann Emerg Med 1997;30:507-12.

12. Dönmez 0, Meral A, Yavuz M, et al. Crush syndrome of children in the Marmara earthquake, Turkey. Pediatr Int 2001;43:678-82.

13. Adams D, de Jonge $\mathrm{R}$, van der Cammen $\mathrm{T}$, et al. Acute kidney injury in patients presenting with hyponatremia. J Nephrol 2011;24:749-55.

14. Adrogue HJ, Madias NE. Hyponatremia. N Engl J Med 2000;342:1581-9.

15. Gonzalez D. Crush syndrome. Crit Care Med 2005;33:S34-41.

16. Bosch X, Poch E, Grau JM. Rhabdomyolysis and acute kidney injury. N Engl J Med 2009;361:62-72.

17. Westermann I, Dünser MW, Haas T, et al. Endogenous vasopressin and copeptin response in multiple trauma patients. Shock 2007;28:644-49.

18. Better OS. Rescue and salvage of casualties suffering from the crush syndrome after mass disasters. Mil Med 1999;164:366-69.

19. Gunal Al, Celiker H, Dogukan A, et al. Early and vigorous fluid resuscitation prevents acute renal failure in the crush victims of catastrophic earthquakes. J Am Soc Nephrol 2004;15:1862-67.

20. Oda J, Tanaka H, Yoshioka T, et al. Analysis of 372 patients with rush syndrome caused by the Hanshin-Awaji earthquake. J Trauma 1997;42:470-76.

21. Sever MS, Erek E, Vanholder R, et al. Clinical findings in the renal victims of a catastrophic disaster: the Marmara earthquake. Nephrol Dial Transplant 2002;17:1942-9.

22. Speedy DB. The drinking athlete. N Z J Sport Med 1996;24:33-4.

23. Rosner MH, Kirven J. Exercise-associated hyponatremia. Clin J Am Soc Nephrol 2007;2:151-61.

24. Corwin HL, Schreiber MJ, Fang LS. Low fractional excretion of sodium: occurrence with hemoglobinuric- and myoglobinuricinduced acute renal failure. Arch Intern Med 1984;144:981-2.

25. Chawla A, Sterns RH, Nigwekar SU, et al. Mortality and serum sodium: do patients die from or with hyponatremia? Clin J Am Soc Nephrol 2011;6:960-5. 